\title{
Nanoscale
}

\section{Experimental review: Chemical reduction of graphene oxide (GO) to reduced graphene oxide (rGO) by aqueous chemistry}

\begin{tabular}{|r|l|}
\hline Journal: & Nanoscale \\
\hline Manuscript ID & NR-ART-04-2017-002943 \\
\hline Article Type: & Paper \\
\hline Date Submitted by the Author: & 25-Apr-2017 \\
\hline Complete List of Authors: & $\begin{array}{l}\text { Guex, Léonard; KTH - Royal Institute of Technology, Fiber and Polymer } \\
\text { Technology } \\
\text { Sacchi, Benedetta; Universita degli Studi di Milano } \\
\text { Peuvot, Kevin; KTH - Royal Institute of Technology, Fiber and Polymer } \\
\text { Technology } \\
\text { Andersson, Richard; KTH - Royal Institute of Technology, Fiber and } \\
\text { Polymer Technology } \\
\text { Pourrahimi, Amir Masoud; Royal Institute of Technology, Fiber and Polymer } \\
\text { Technology } \\
\text { Strom, Valter; Royal Institute of Technology, Material Science } \\
\text { Farris, Stefano; University of Milan, Food Science and Microbiology } \\
\text { Olsson, Richard; Royal Institute of Technology, Fiber and Polymer } \\
\text { Technology }\end{array}$ \\
\hline \hline
\end{tabular}




\section{Nanoscale Guidelines to Referees}

Nanoscale (www.rsc.org/nanoscale) s a community-spanning journal publishing very high quality, high impact research across nanoscience and nanotechnology.

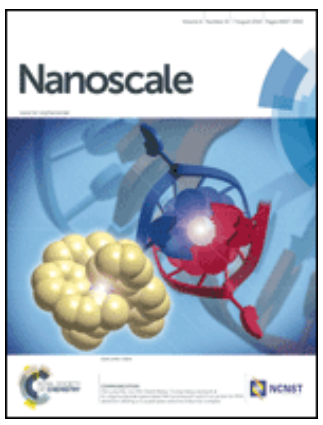

\section{Nanoscale's latest Impact Factor is 7.760}

\section{We aspire to even higher values in future years}

\section{Nanoscale Associate Editors stress very high standards for acceptance in the journal. Articles must report extremely novel, very high quality, reproducible new work of broad general interest.}

As a referee, our Associate Editors strongly encourage you to recommend only the best work for publication in Nanoscale. Since launch in late 2009, Nanoscale has quickly become a leading journal. We aspire for the journal to publish truly world-class research.

Routine, limited novelty or incremental work - even if competently researched and reported - should not be recommended for publication. Nanoscale demands high novelty and high impact.

We strongly discourage fragmentation of work into several short publications. Unnecessary fragmentation is a valid reason for rejection.

Thank you very much for your assistance in evaluating this manuscript, which is greatly appreciated.

With our best wishes,

Chunli Bai (Editor-in-Chief)

Xiaodong Chen, Serena Corr, Yves Dufrêne, Andrea Ferrari, Dirk Guldi, Xingyu Jiang, RongChao Jin, Yamuna Krishnan, Jie Liu, Xiaogang Liu, Wei Lu, Francesco Stellacci, Shouheng Sun, Jianfang Wang, Hongxing Xu, Xiao Cheng Zeng (Associate Editors)

\section{General Guidance (For further details, see the Royal Society of Chemistry's Refereeing Procedure and Policy)}

Referees have the responsibility to treat the manuscript as confidential. Please be aware of our Ethical Guidelines which contain full information on the responsibilities of referees and authors.

When preparing your report, please:

- Comment on the originality, importance, impact and scientific reliability of the work;

- State clearly whether you would like to see the paper accepted or rejected and give detailed comments (with references) that will both help the Editor to make a decision on the paper and the authors to improve it;

Please inform the Editor if:

- There is a conflict of interest;

- There is a significant part of the work which you are not able to referee with confidence;

- If the work, or a significant part of the work, has previously been published, including online publication, or if the work represents part of an unduly fragmented investigation.

When submitting your report, please:

- Provide your report rapidly and within the specified deadline, or inform the Editor immediately if you cannot do so. We welcome suggestions of alternative referees.

If you have any questions about reviewing this manuscript, please contact the Editorial Office at nanoscale@rsc.org 


\section{Journal Name}

\section{Experimental review: Chemical reduction of graphene oxide (GO) to reduced graphene oxide ( $\mathrm{rGO}$ ) by aqueous chemistry}

Received 00th January 20xx, Accepted 00th January 20xx

DOI: $10.1039 / x 0 x \times 00000 x$

www.rsc.org/

\author{
L. G. Guex, ${ }^{\text {a B. Sacchi, }}{ }^{\text {b }}$ K. F. Peuvot, ${ }^{\text {a }}$ R. L. Andersson, ${ }^{a}$ A. M. Pourrahimi, V. Ström, ${ }^{c}$ S. Farris, ${ }^{d}$ and \\ R. T. Olsson ${ }^{a,} \dagger$
}

\section{Introduction}

A growing area of science is the use of reduced graphene oxide ( $\mathrm{rGO}$ ) in different polymeric materials. ${ }^{1}$ The interest stems from the possibility to prepare conductive composites with tailored electrical characteristics, possibly also making use of the inherent high mechanical properties related to strong and stiff $\mathrm{sp}^{2}$-hybridized sheets of interconnected carbon atoms. ${ }^{2-5}$ At the same time, most of the articles concerning the applied use of rGO relies on the Hummers method, which serves to exfoliate sheets of graphene oxide (GO) from graphite. ${ }^{6}$ The method presents a robust laboratory route to the raw material and is beneficial due to the natural dispersion of the sheets that results from the introduced surface polarity, which in turn serves to facilitate separation of the sheets in

\footnotetext{
a. Department of Fibre and Polymer Technology, School of Chemical Science and Engineering, KTH Royal Institute of Technology, Stockholm, Sweden.

${ }^{b}$ Department of Chemistry, University of Milan, via Golgi 19- 20133 Milan, Italy.

c. KTH Royal Institute of Technology, School of Industrial Engineering and

Management, Material Science and Engineering, SE-100 44 Stockholm, Sweden.

d. DeFENS, Department of Food, Environmental and Nutritional Sciences-

Packaging Division, University of Milan, Via Celoria 2 - 20133 Milan, Italy.

+ Corresponding author: Richard T. Olsson, E-mail: rols@kth.se

Electronic Supplementary Information (ESI) available: See DOI: 10.1039/x0xx00000
}

aqueous media. The structure of the $\mathrm{GO}$ is assumed to be a network of $\mathrm{sp}^{2}$-hybridized $-\mathrm{C}-\mathrm{C}$ - atoms, with a considerable amount of $\mathrm{sp}^{3} \mathrm{C}-\mathrm{O}$ bonds (up to $55 \%$ ) from oxygen in the form of carboxyl, hydroxyl or epoxy groups. ${ }^{7}$ However, the polar oxygen units not only bring positive consequences in terms of a facilitated aqueous dispersion, but also a downside with a very substantial decrease in sheet conductivity. Efficient removal of these oxygen species for the preparation of reduced graphene oxide ( $\mathrm{rGO}$ ) is therefore important for any application concerning non-linear and linear conductive polymer nanocomposites. ${ }^{8-11}$

An increasing carbon to oxygen ratio in the sheets should in theory result in higher conductivity, however, for similar $\mathrm{C} / \mathrm{O}$ ratios of ca. 7 , the reported conductivities range from 45 to $15000 \mathrm{~s} / \mathrm{m} .{ }^{12}$ Also, conductivity values for different reduction protocols not only vary enormously depending on the used reducing agent $\left(10^{-1}\right.$ to $\left.10^{3} \mathrm{~S} / \mathrm{m}\right)$, but also for rather similar reduction routes, e.g. using $\mathrm{NaBH}_{4}$ from $10^{-1}$ to $10^{2} \mathrm{~S} / \mathrm{m} .{ }^{12-14}$ This situation complicates any prediction of the conductivities for rGO composite material formulations, and affects the reliability of any theoretical model or simulation. ${ }^{15}$ However, since the electrical conductivity of a rGO-based substrate is also dependent on geometrical aspects like sheet orientation 
and percolation effects, the gross diversity of reported conductivities is not surprising.

This article aims to describe thoroughly the morphological changes and how the electrical conductivity develops with time by reducing $\mathrm{GO}$ into $\mathrm{rGO}$. The reducing agent was sodium borohydride $\left(\mathrm{NaBH}_{4}\right)$ and the reduction was initially performed at different temperatures. The development of electrical conductivity with increased reduction time is also investigated by Raman spectroscopy and X-ray photoelectron spectroscopy (XPS), monitoring the increasing conductivity with a decreasing amount of $\mathrm{C}-\mathrm{O}$ bonds (e.g. epoxy/hydroxyl groups). This correlation between the decreasing presence of $\mathrm{C}-\mathrm{O}$ bonds and degree of reduction is further supported by a dramatic loss of mechanical integrity of freeze-dried nanofoams of the rGO. Finally, it is demonstrated that the provided reduction protocol results in $\mathrm{rGO}$ sheets with more than 1 order of magnitude higher conductivity than previously reported for aqueous reduction routes of $\mathrm{GO}$ using sodium borohydride $\left(\mathrm{NaBH}_{4}\right)$. The electrical properties obtained by 4-probe sheet resistivity measurements are presented in depth and discussed in relation to the nature of filtrate sheet assemblies of stacked $\mathrm{GO} / \mathrm{rGO}$ sheets used as a substrate for the measurements.

\section{Experimental}

\section{Materials}

Graphene oxide was purchased as an aqueous suspension with a 0.5 wt.\% solid GO content (NO02-PS-0.5), from Angstrom Materials in Dayton (USA). The confirmed average lateral $x / y$ dimensions were ca. $500 \mathrm{~nm}$ (TEM) and the thickness 1-1.2 nm (according to the manufacturers' AFM measurements). Reagent grade sodium borohydride $\left(\mathrm{NaBH}_{4}\right)$ was used as obtained from Sigma-Aldrich. Sodium hydroxide $(\mathrm{NaOH})$, and ca. $30 \%$ ammonium hydroxide solution were purchased from Fluka and used as alkaline buffer solution to prevent aqueous depletion (hydrolysis) of the $\mathrm{NaBH}_{4}{ }^{16}$ The chemicals were all of analytical reagent grade or equivalent and they were used as received without further purification.

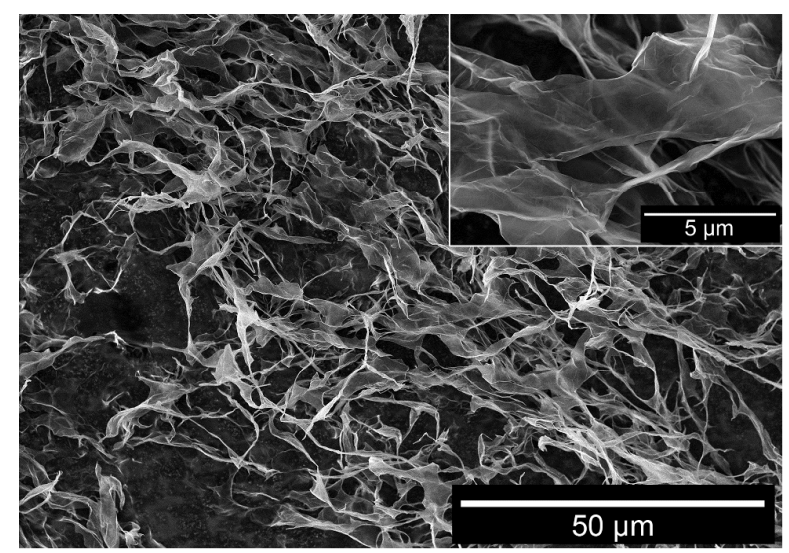

Fig. 1 The micrograph shows the pristine graphene oxide obtained from the Angstrom laboratories, after freeze-drying $2 \mathrm{~mL}$ directly post quenching in liquid nitrogen.

\section{Methods and Characterisation}

Procedure for chemical reduction:

A $12 \mathrm{~mL}$ master solution was prepared using $7.67 \mathrm{~mL}$ of Milli-Q water, $4.33 \mathrm{~mL}$ of a 10 vol.\% saturated $\mathrm{NaOH}$ buffer solution and $227 \mathrm{mg}$ of $\mathrm{NaBH}_{4}$ reducing agent. The chemical reduction was conducted under magnetic stirring, using $1.2 \mathrm{~mL}$ of the master solution and $0.8 \mathrm{~mL}$ of graphene oxide solution in sealed glass vials placed in aluminium blocks on a Pierce Reacti-Therm III heating/stirring module. After the desired reaction time ( $2 \mathrm{~min}$ to $24 \mathrm{~h}$ ), the samples were transferred into $2 \mathrm{~mL}$ Eppendorf tubes and immediately cooled in an icebath, centrifuged at $13400 \mathrm{rpm}$ for 30 minutes after which the water was replaced. This operation was repeated three times in order eliminate residual ions from the salts from the $4 \mathrm{mg}$ rGO prepared in each vial. The same protocol was evaluated at $20,40,60$ and $80^{\circ} \mathrm{C}$.

Procedure for filtration and film substrate preparation: The filtration was carried out by a vacuum pump, using polycarbonate (PC) filter holders for the $25 \mathrm{~mm}$ diameter PC filters with pore channels of $0.8 \mu \mathrm{m}$, and cellulose pads as support for the PC filters. The prepared $\mathrm{GO} / \mathrm{rGO}$ suspensions were filtered through the $\mathrm{PC}$ filters as evenly as possible and were finally air dried at $23{ }^{\circ} \mathrm{C}$, under ambient pressure, before the electrical measurement at $45 \%$ relative humidity. The obtained $\mathrm{GO} / \mathrm{rGO}$ sheet assembly (film) had a diameter of 21.8 $\mathrm{mm}$ and a thickness of $6 \pm 2 \mu \mathrm{m}$. The PC filters with $0.015,0.2$, 0.8 and $3 \mu \mathrm{m}$ channels were purchased from Whatman as Nuclepore as Track-etch membranes.

Procedure for $\mathrm{rGO}$ nanofoam preparation:

The rGO nanofoams formation was evaluated from identical samples as used for the preparation of the filtrate films, but with the difference that the samples prepared for filtration were rapidly frozen in liquid nitrogen and subsequently freezedried, using a CoolSafe freeze drier (ScanVac) operating at $0.060 \mathrm{hPa}$ and $-96^{\circ} \mathrm{C}$ for 48 hours.

Electrical measurements:

The electrical characterization of the samples was carried out on the $\mathrm{GO} / \mathrm{rGO}$ sheet assembly (film) obtained on the $0.8-\mu \mathrm{m}$ PC filters, with particular attention to the samples' geometry in order to get reproducible values. These vacuum filtrated $\mathrm{rGO}$ substrates were found to be ideal with a uniform thickness and with the flakes aligned parallel to the surface of the film, i.e. parallel to the current. The sheet resistance of each film was measured with a 4-wire collinear probe with $5 \mathrm{~mm}$ probe spacing, connected to a Keithley 2450 SourceMeter. This allowed for an average of several confirmative measurements on each film simply by moving the probe to different locations (at least 5). A geometrical correction factor of 3.36 was used to compensate for finite sheet sizes, i.e. the film diameter was 5 times the contact distance and the thickness was much less than the probe spacing (a correction factor of $\pi / \ln (2)=4.53$ is normally used for "infinitely" large and thin films). ${ }^{17,18}$ The 
outer contacts carried the probing current into and out of the sample, and the two inner contacts enabled the determination of the voltage drop (removing the influence of contact resistance on the measurement). The measured sheet resistance was combined with the measured thicknesses of the films in order to calculate the volumetric conductivity.

Microscopy:

A field emission scanning electron microscope (FE-SEM), Hitachi S-4800, was used for $\mathrm{GO} / \mathrm{rGO}$ sample sheet imaging. The samples were peeled off from the polycarbonate filter support and mounted at an angle towards the electron source, or placed directly on the sample holder carbon tape as freezedried nanostructured foams. The pristine $\mathrm{GO}$ and the 2 and 8 min $\mathrm{rGO}$ samples were sputtered with $\mathrm{Pt} / \mathrm{Pd}$ (60/40) (under Argon) for $20 \mathrm{~s}$ at a current of $80 \mathrm{~mA}$.

\section{X-ray photoelectron spectroscopy (XPS) and Raman spectroscopy:}

XPS measurements were performed in an M-Probe instrument (Surface Science Instruments, USA) equipped with a monochromatic Al $\mathrm{K} \alpha$ source $(1486.6 \mathrm{eV})$ with a spot size of $200 \mu \mathrm{m} \times 750 \mu \mathrm{m}$ and a pass energy of $25 \mathrm{eV}$, providing a resolution of $0.74 \mathrm{eV}$. The energy scale was calibrated with reference to the $4 f_{7 / 2}$ level of a freshly evaporated gold sample, at $84.0 \pm 0.1 \mathrm{eV}$, and with reference to the $2 \mathrm{p}_{3 / 2}$ and $3 \mathrm{~s}$ levels of copper at $932.47 \pm 0.1$ and $122.39 \pm 0.15 \mathrm{eV}$, respectively. With a monochromatic source, an electron flood gun was used to compensate for the build-up of positive charge on the insulating samples during the analyses: a value of $10 \mathrm{eV}$ was selected for these samples to be measured. For all the samples (pristine GO and rGO after 2, 4, 8, 16, 32, 64, 128, 192, and 1440 min of reduction treatment), the aliphatic carbon $C$ is peak level was taken as an internal reference at $284.6 \mathrm{eV}$. Wide-scan XPS survey spectra were used to gather information on the surface atomic composition of pristine GO samples and $\mathrm{rGO}$ samples. High-resolution spectra of $\mathrm{C} 1 \mathrm{~s}$ were used to determine the carbon functionalities of $\mathrm{GO}$ and rGO. ESCA Hawk v 1.01 software was used to perform curve fitting and to calculate the atomic concentrations. Raman spectra were recorded at ambient temperature with an inVia confocal Raman spectrometer (Renishaw, Wotton-under-Edge, UK) with an Ar-ion laser at an excitation wavelength of $514.5 \mathrm{~nm}$. 


\section{Results and discussion}

\section{A method for reproducible electrical measurements}

Figure 2 shows the outcome of 4 different attempts to form a solid film of reduced graphene oxide $(\mathrm{rGO})$ for proper 4-point probe electrical measurements.
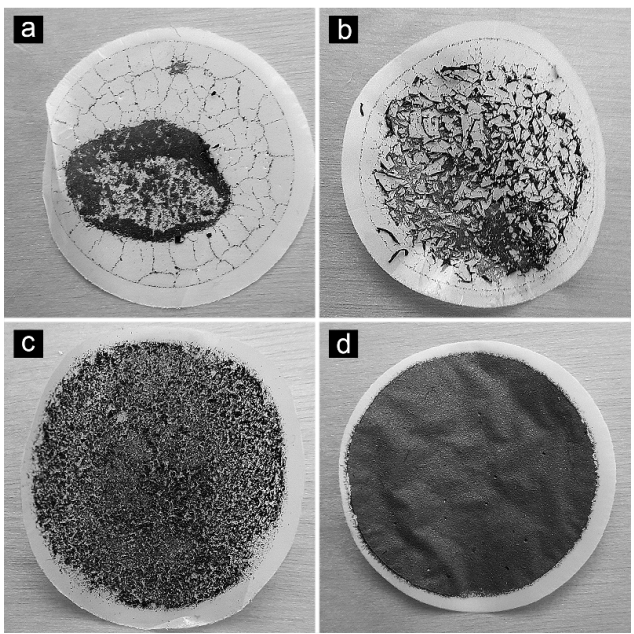

Fig. 2 shows examples of (a-b) non-uniform deposition and excessive phase separation before extraction of the aqueous phase, (c) even deposition but partial phase separation, and (d) the results of the sequential and even deposition of the $\mathrm{GO} / \mathrm{rGO}$ aqueous suspension. Every filter contains $4 \mathrm{mg}$ of sample.

The film uniformity varied and depended not only on the nature of support film used for deposition of the sheets but also on the degree of reduction of the rGO. From several attempts of filtration it could be concluded that a uniform film formation of the pristine GO frequently did not form. Instead, the $\mathrm{GO}$ as well as the partially reduced $\mathrm{rGO}$ flocculated in the water phase and resulted in a leopard-like pattern of small separated $\mathrm{GO} / \mathrm{rGO}$ domains on drying, so the conductivity determinations were unreliable and of little use. The patterns visible in Fig. 2 a-c was attributed to aggregation and flocculation of the anisotropic shaped nanoparticles in the aqueous suspensions. ${ }^{19-20}$

The key to obtaining a coherent and uniform film (see Fig. 2d) was to deposit the solution in a sequential manner of ca. $200 \mu \mathrm{L}$ droplets with intermediate vortex shaking, allowing the $\mathrm{GO} / \mathrm{rGO}$ to stabilize as an even deposit before applying additional droplets in combination with vacuum assisted filtration. Figure $3 a$ shows the cross-sectional view of the reduced GO sheets (Fig $2 \mathrm{~d}$ ) stacked as overlapping sheets in a film that could be peeled off from the support filter. Fig. 3c shows an illustration of the filtration set-up used for preparing the uniform stacked sheet films. A partially polar polycarbonate (PC) filter was found to provide a good balance in filter hydrophobicity, compared to using hydrophilic cellulose filters or more hydrophobic filters such as Teflon (polytetrafluoroethylene, PTFE) filters. This was due to the nature of the PC filter, allowing a uniform film formation over the entire range of different surface polarities of the $\mathrm{GO} / \mathrm{rGO}$ sheets that were obtained after different times of reduction, i.e. with decreasing presence of oxygen (see section 3). The vacuum-assisted filtration method further relied on enforcing the water phase through the $0.8 \mu \mathrm{m}$ PC filter channels at 0.8 bar relative pressure, resulting in the sheets deposited as inplane oriented flakes parallel to the filter surface (Fig. 3b and $3 c$ inset). Finer filters with smaller channels ( 0.015 and $0.2 \mu \mathrm{m})$ did not allow the water passage within reasonable filtration times $(<1 \mathrm{~h})$ and required sometimes more than 6 hours for complete filtration, or the $\mathrm{GO} / \mathrm{rGO}$ suspension tended to pass over the rim of the filter rather than via the filter channels. The use of filters with $3 \mu \mathrm{m}$ channels did not allow for all the $\mathrm{GO} / \mathrm{rGO}$ material to be retained on the filter surface and the filtrate contained extensive amounts of $\mathrm{GO} / \mathrm{rGO}$ material.

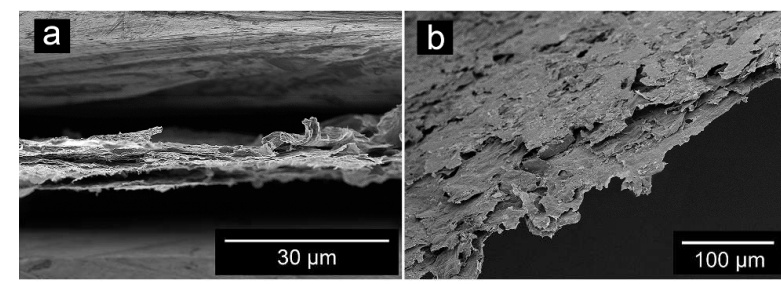

c

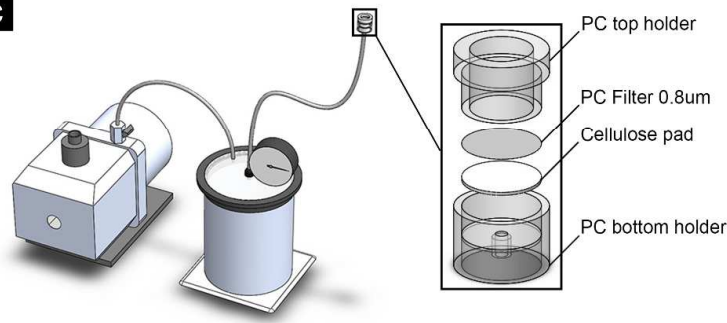

Fig. 3. (a) shows that the thickness of the obtained filter $\mathrm{GO} / \mathrm{rGO}$ sheet assembly (film) using the vacuum-assisted filtration was $6 \pm 2 \mu \mathrm{m}$. (b) shows that the filter sheet assemblies' are consisting of overlapping $\mathrm{GO} / \mathrm{rGO}$ sheets. (c) shows the used filtration set-up operated at 0.8 bar

Fig. 4 emphasizes the importance of using an adequate filtration technique for the preparation of substrates aimed for electrical measurements. The conductance decreased ca. 1 order of magnitude only as a result of replacing the above vacuum-assisted filtration with evaporation of the water phase overnight in a $0 \%$ R.H. desiccator. It is noteworthy that the same mass of $\mathrm{GO} / \mathrm{rGO}$ was used for the preparation of all the films in Fig 4. Further, the difference in conductance for identically reduced $\mathrm{GO}$ was explored by freeze-drying the water-suspended rGO into a porous powder for the preparation of compressed film substrates. The conductance decreased an additional ca. 1000 times for the freeze-dried material, i.e. compare measurements above $40^{\circ} \mathrm{C}$, Fig. 4 . The explanation to the different conductance for the identically reduced GO was accordingly only related to the compactness of the prepared substrates. The inset in Fig. 4 illustrates how the difference in the conductance between the differently prepared substrates can be explained from an electrical perspective. A slow evaporation of the aqueous phase during extended time resulted in films that were to greater extent affected by rGO phase segregation during the evaporation, e.g. a more porous filter sheet assembly formed with fewer 
electrical contact points between the sheets. The freeze-drying resulted in an even more loosely packed rGO sheet assembly. On the contrary, substrates obtained via the vacuum-assisted filtration constituted more of a continuous electrical entity and thus result in conductance values more representative for the individual sheets. However, in none of the cases the sheets can be presumed to be in perfect and full electrical contact and thus suffer from a substantial flake-to-flake resistance. An increase in conductance with compaction of non-oriented graphene sheets assemblies was previously reported by Marinho et al., i.e. demonstrating increasing conductance with increasing number of contact points for dry graphene. ${ }^{21}$

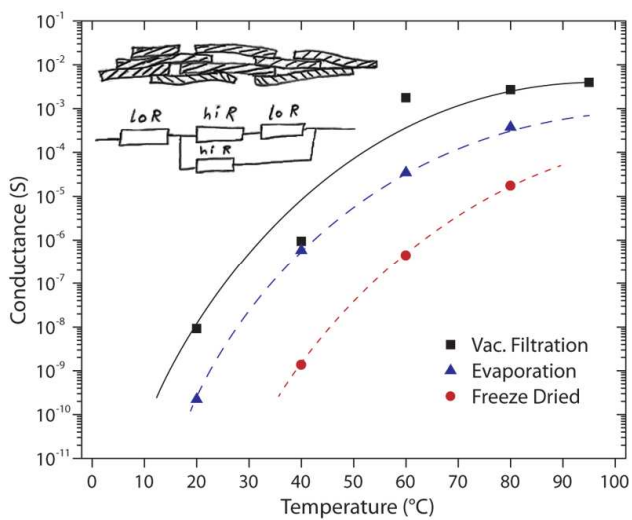

Fig. 4. The markers represent conductance values for samples prepared individually at $20,40,60$ and $80^{\circ} \mathrm{C}$, after 3 repetitive water cleaning cycles followed by film formation. Black markers (square) show the effect of the vacuum assisted filtration technique for preparation of a more compact film, blue markers (triangle) show the results for ambient condition evaporation over $24 \mathrm{~h}$, and red markers (circles) show the conductance obtained for $\mathrm{GO} / \mathrm{rGO}$ as a freeze dried powder prepared into a film.

From Fig. 4 it is also apparent that a reduction carried out at $>60{ }^{\circ} \mathrm{C}$ was favourable for the preparation of more conductive samples, showing 4-6 orders of magnitude higher conductance after 2 hours of reduction. All the subsequent measurements were therefore conducted on samples prepared using the vacuum-assisted filtration, and a time optimization of the experimental reduction protocol was carried out at a reaction temperature of $80^{\circ} \mathrm{C}$. Until now all the numbers for the electrical conductivity have been given as conductance (SI unit is Siemens, S), for a given amount of material, enabling comparisons related solely to the orientation and compactness of the sheets after the film formation. With vacuum-assisted filtration, reproducible thicknesses and in-plane $\mathrm{GO} / \mathrm{rGO}$ orientations are obtained, motivating that the results are reported as calculated volume conductivity $(\mathrm{S} / \mathrm{m})$, which facilitates comparisons with literature values. The densities of the sheet assemblies were derived as $1.78 \pm 0.67 \mathrm{~g} / \mathrm{cm}^{3}$ from the $21.8 \mathrm{~mm}$ diameter of the sheet assembly with a cross-sectional thickness of $6 \pm 2 \mu \mathrm{m}$ (Fig. $2 \mathrm{~d}$ and $3 \mathrm{a}$ ), consisting of $4 \mathrm{mg}$ of $\mathrm{GO} / \mathrm{rGO}$ material. The value reflects that even if highly reproducible samples could be obtained, the samples were still porous (as can be seen from Fig. 3a). The crystal density of graphite is $2.26 \mathrm{~g} / \mathrm{cm}^{3}{ }^{22}$

\section{Conductivity increase with time for $\mathrm{NaBH}_{4}$ as reducing agent}

Figure 5 shows the conductivity for a sequence of separately prepared GO samples reduced for increasing times, using the same amount of $300 \mathrm{mM} \mathrm{NaBH}_{4}$ reducing agent for the $4 \mathrm{mg} \mathrm{GO}$ content in each sample $\left(80^{\circ} \mathrm{C}\right)$. It is notable that the dominant part of the reduction of the $\mathrm{GO}$ occurred within the first 10-15 $\mathrm{min}$ (Fig 5). After 20 minutes, the reduction progressed at a considerably slower rate until a conductivity of ca. $1500 \mathrm{~S} / \mathrm{m}$ was reached.

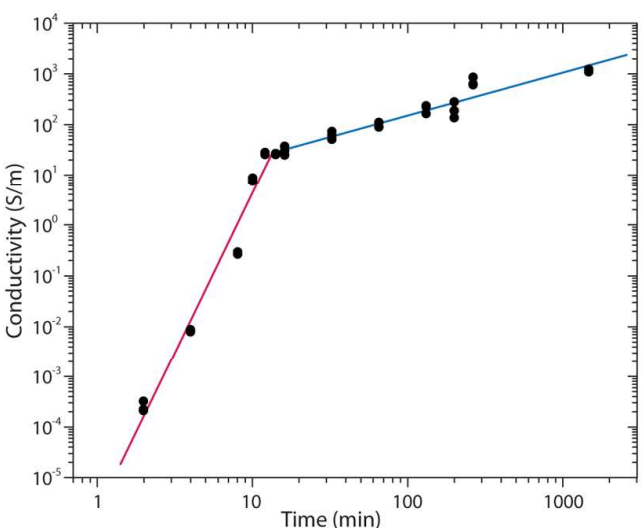

Fig. 5 Red (steeper) line shows the increase in conductivity with reduction time during the first 16 minutes, blue line shows the smaller increase in conductivity with time after ca. 20 minutes of reaction. The conductivity was calculated from the measured conductance and the average thickness of the samples of $6.0 \mu \mathrm{m}$ (Fig. 3a).

This two-phase electrical conductivity vs. time evolution was very distinct, and corresponded to a conductivity increase of 5 orders of magnitude in the time frame from 0 to $16 \mathrm{~min}$ (red line), whereas after 16 min the conductivity increased more moderately by an additional two orders of magnitude in a time frame of ca. $1400 \mathrm{~min}$ ( $24 \mathrm{~h}$, blue line). Table 1 shows that the rGO reduction route resulted in the highest conductivity values reported so far for aqueous reduction of graphene oxide, using sodium borohydride.

Table 1. Conductivities of reduced graphene oxide ( $\mathrm{rGO}$ ), time and temperature for reduction, from previous articles. The conductivity for graphite refers to the in-plane direction (perpendicular to the c-axis). ${ }^{22}$ This work's data were obtained at $45 \%$ R.H. $\left(23^{\circ} \mathrm{C}\right)$. The ${ }^{*}$-value refers to the conductivity of the same $\mathrm{GO}$ sample measured after storing in a sealed desiccator for $12 \mathrm{~h}\left(23^{\circ} \mathrm{C}\right) .{ }^{23,24}$

\begin{tabular}{cccccc}
\hline Material & $\begin{array}{c}\text { Reducing } \\
\text { agent }\end{array}$ & $\begin{array}{c}\text { Temp } \\
\left({ }^{\circ} \mathrm{C}\right)\end{array}$ & $\begin{array}{c}\text { Time } \\
(\text { min })\end{array}$ & $\begin{array}{c}\text { Conductivity } \\
(\mathrm{S} / \mathrm{m})\end{array}$ & [Ref] \\
\hline rGO & $\mathrm{NaBH}_{4}$ & 95 & $45 / 15$ & $1.55 / 0.26$ & 13 \\
rGO & $\mathrm{NaBH}_{4}$ & 80 & 60 & 17 & 46 \\
rGO & $\mathrm{NaBH}_{4}$ & $\mathrm{~N} / \mathrm{A}$ & 120 & 45 & 47 \\
rGO & $\mathrm{NaBH}_{4}$ & 80 & 60 & 82.3 & 14 \\
rGO & $\mathrm{NaBH}_{4}$ & 80 & 1440 & 1500 & This work \\
GO & - & - & - & $0.00030,8 \mathrm{E}-6 *$ & This work \\
Graphite & - & - & - & $\sim 300000$ & 22 \\
\hline
\end{tabular}




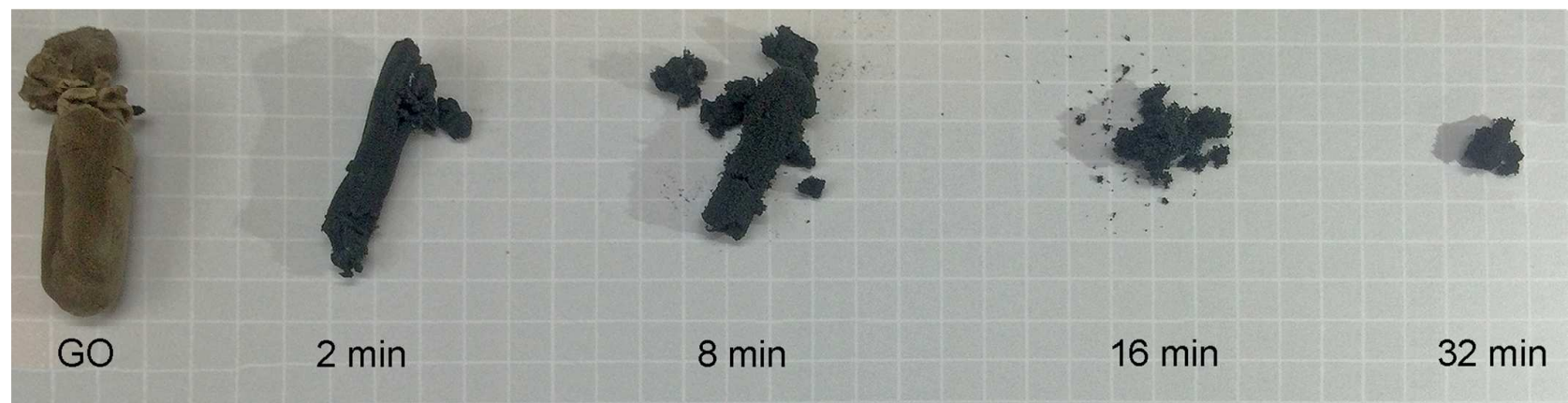

Fig. 6. The photograph shows the loss of structural integrity for freeze-dried graphene oxide with increasing times of reduction. After 16 minutes the ability to form foams by freeze-drying has been completely lost. All samples were dried in the same container and all samples contained $4 \mathrm{mg}$ of $\mathrm{GO} / \mathrm{rGO}$. The background is a $5 \mathrm{~mm}$ square grid.

Considering the importance of a controlled consolidation of the probed sheets in combination with a reliable conductivity determination we argue that much of the variation found in Table 1 might be due to preparation and measuring techniques. This may in fact even explain why a higher carbon to oxygen ratio shows lower conductivity than expected for equal presence of oxygen after almost identical reductions. ${ }^{12}$ An additional or alternative explanation accounts for humidity and possible contaminations present on the $\mathrm{GO} / \mathrm{rGO}$ or graphene sheets prior to the preparation of the dry electrical substrate. These ions may originate from the used reducing agent (i.e. $\mathrm{Na}^{+}$in this work), but also from the $\mathrm{NaOH}$ salt used for the preparation of the alkaline medium used to prevent dissociation reactions of the borohydride. ${ }^{16} \mathrm{~A}$ MilliQ water exchange for a minimum of three times, with intermediate ultra-sonication treatment was previously reported as a useful approach to obtain $\mathrm{ZnO}$ nanoparticles with significantly reduced presence of counter ions and other contaminations. ${ }^{25}$

\section{Impact on nanofoam morphology from degree of reduction}

The picture in Fig. 6 shows the changes from a light brown pristine $\mathrm{GO}$ into a pitch black partially reduced $\mathrm{GO}$ already after 2 minutes of reaction. Fig. 6 also demonstrates that the pristine GO shows a capability to stabilize a foam structure with virtually no shrinkage during freeze-drying. As the reduction progressed this feature disappeared. The 2 and 4 min samples shrunk ca. 50-60\% in volume while still maintaining sufficient structural integrity to be lifted with tweezers. The $8 \mathrm{~min}$ sample could not be held by tweezers without falling apart. After $16 \mathrm{~min}$ reaction, the foam had collapsed already at the stage of removal of the samples from the freeze dryer. All tubes contained ca. $4 \mathrm{mg} \mathrm{GO} / \mathrm{rGO}$ at the moment of freezing in liquid nitrogen, and were dried in the same freeze-dryer container. It is suggested that the primary reason for the disappearance of the foam structure was related to the removal of the oxygen from the surface of the rGO/GO. Table 2 shows that the ratio of carbon to oxygen increased from 2.2 to $6.9 \mathrm{C} / \mathrm{O}$ due to the reductions of the GO, and although small morphology changes occurred (see morphology section), the most substantial changes within the samples were related to the elimination of surface located oxygen atoms. The elimination of oxygen also manifested itself in terms of dispersion/aggregation of the suspended $\mathrm{GO} / \mathrm{rGO}$ sheets before drying. The partially reduced GO sheets obtained within the first 8 min required more than 15 minutes to filtrate into solid sheets, whereas the entire filtration procedure was over in only a couple of seconds for GO reduced 16 minutes or longer. In summary, at the knee in Fig. 5 , the ability to form nanofoams was lost at the same time as the filtration into a film occurred more than 1000 times faster, i.e. within a few seconds.

\section{Reduction outcome in terms of elimination of surface oxygen}

Carbon, oxygen, and sodium elemental percentage proportions calculated from the wide-scan XPS spectra of GO and $\mathrm{rGO}$ samples are shown in Table 2, together with the carbon/oxygen ratio. The elemental composition of the pristine GO included carbon and oxygen at an atomic percentage of 68.69 and 31.31 at\%, respectively, which is in line with recent literature data. ${ }^{26,27}$

Table 2. Elemental surface analysis (atom.\%) and C/O atomic ratio of graphene oxide (GO) and chemically reduced $\mathrm{GO}(\mathrm{rGO})$ at different reaction times determined by XPS.

\begin{tabular}{ccccc}
\hline Reduction $(\mathrm{min})$ & $\mathrm{C}$ & $\mathrm{O}$ & $\mathrm{Na}$ & $\mathrm{C} / \mathrm{O}$ \\
\hline $\mathrm{GO}(0 \mathrm{~min})$ & 68.69 & 31.31 & -- & 2.19 \\
2 & 72.02 & 23.85 & 4.13 & 3.02 \\
4 & 75.18 & 21.06 & 3.76 & 3.57 \\
8 & 78.35 & 18.28 & 3.37 & 4.29 \\
16 & 80.52 & 16.57 & 2.91 & 4.86 \\
32 & 82.66 & 14.89 & 2.45 & 5.55 \\
64 & 83.95 & 13.77 & 2.28 & 6.10 \\
128 & 85.24 & 12.67 & 2.09 & 6.73 \\
192 & 85.61 & 12.35 & 2.04 & 6.93 \\
1440 & 84.80 & 12.35 & 2.85 & 6.87 \\
\hline
\end{tabular}

The relative amount of oxygen decreased while the amount of carbon increased with reduction time, with the concurrent presence of sodium arising from the reagents used during the reaction, see Fig 7. Overall, the reduction resulted in an increase in the $\mathrm{C} / \mathrm{O}$ value from 2.2 for the pristine $\mathrm{GO}$ to 6.9 for the longer reaction times, as can also be seen from the 


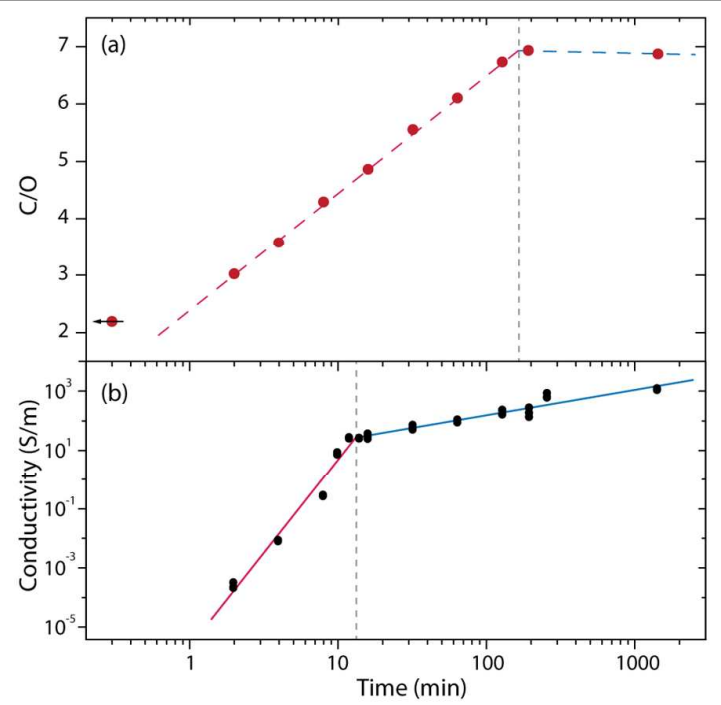

Fig. 7. (a) XPS data. Evolution of $\mathrm{C} / \mathrm{O}$ ratio as a function of the reaction time for reduction of $\mathrm{GO}$ by $\mathrm{NaBH}_{4}$ in $\mathrm{NaOH}$ buffer solution. (b) conductivity as a function of the reaction time (from Fig. 5).

survey spectra of GO and rGO after $24 \mathrm{~h}$ treatment (see supplementary information, Figure S1). It is interesting to note that a steep linear increase is observed until ca. 2.1 hours (128 min treatment), after which $\mathrm{C} / \mathrm{O}$ values started to vary more slowly until reaching a plateau, where the $\mathrm{C} / \mathrm{O}$ value was almost constant at around 6.8 , see Fig $7 \mathrm{a}$. The break point corresponding to the slower increase in conductivity with increasing reaction time was however occurring more than two hours earlier, i.e. compare Fig. $7 a$ and b. This suggests that while reduction generically allowed eliminating oxygen (thus increasing $\mathrm{C} / \mathrm{O}$ ), it had not the same effect on the conductivity of the rGO sheets, probably due to the type of oxygen-carrying carbon atoms involved.

A more detailed information on the functional groups involved in the reduction of GO was obtained by the deconvoluted high-resolution C 1s XPS spectra of GO and rGO, which are displayed in Figure 8 . The high-resolution C1s spectrum of GO exhibited a saddle-like pattern, which is a signature of extreme oxidization in $\mathrm{GO} .{ }^{28} \mathrm{GO}$ is an atomically thin sheet of carbon covalently bonded with functional groups containing oxygen containing $\mathrm{sp}^{2}$ and $\mathrm{sp}^{3}$ hybridized carbon atoms. ${ }^{29}$ In addition to the $\mathrm{sp}^{2}$ graphitic component and $\mathrm{sp}^{3}$ hybridization, deconvolution of the $\mathrm{C} 1 \mathrm{~s}$ peak in $\mathrm{GO}$ disclosed the presence of oxygen-carrying functional groups. The component at $287 \mathrm{eV}$ is assigned to $\mathrm{C}$ atoms directly bonded to oxygen (hydroxyl and epoxy configurations), whereas the component at $288.8 \mathrm{eV}$ is assigned to carbonyl groups. ${ }^{30}$ The high-resolution $\mathrm{C} 1 \mathrm{~s}$ spectrum of all reduced $\mathrm{GO}$ samples exhibited a shift from the double peak seen for the pristine GO to a single sharp peak toward low binding energies, which is indicative of a trend to restore the $\mathrm{sp}^{2}$ bonding graphene configuration. ${ }^{28}$ At the same time, the peaks associated with the oxidized carbon decreased in intensity (Figure 8).
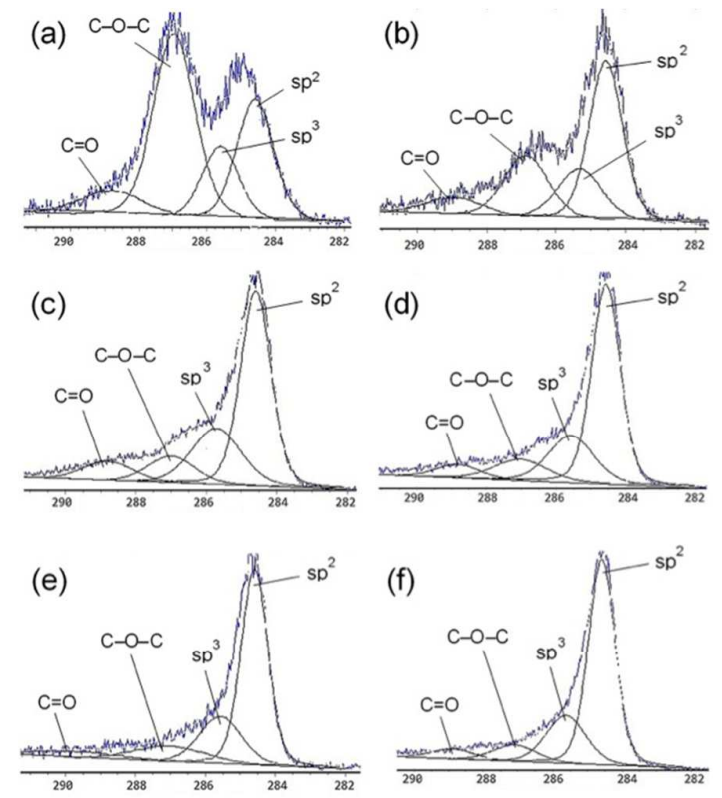

Binding energy (eV)

Fig. 8. XPS data. High-resolution C 1s XPS spectra of graphene oxide (a) and chemically reduced GO after $2 \mathrm{~min}$ (b), $8 \mathrm{~min}$ (c), $32 \mathrm{~min}$ (d), $128 \mathrm{~min}$ (e), and 192 $\min (f)$ reaction times.

The deconvolution data allowed a better understanding of the impact of the reducing treatment on the different oxygenbased functional groups. Table S1 includes the percentage contribution of each functional group assigned after deconvolution of the $\mathrm{C} 1 \mathrm{~s}$ spectra of $\mathrm{GO}$ and $\mathrm{rGO}$ at different reaction times, plotted in Fig 9a. At the beginning of the reaction, the reducing agent acted on the $\mathrm{C}-\mathrm{O}$ functional groups, which decreased from $46.65 \%$ in pristine $\mathrm{GO}$ to approximately $11.5 \%$ in $\mathrm{rGO}$. Interestingly, this dramatic reduction took place in the first $8 \mathrm{~min}$ of treatment, after which the percentage contribution of $\mathrm{C}-\mathrm{O}$ functionalities did not vary significantly. Also noteworthy is the fact that the carbonyl groups were apparently unaffected by the reducing treatment during the first 8 minutes of the reaction ( $C=0$ concentration fixed at $\sim 9 \%$, see Table S1 and Fig. 9). However, after this time span, the $\mathrm{C}=\mathrm{O}$ percentage started to decrease down to $\sim 5 \%$ after 192 min of treatment, see Fig. 9, which coincided with the stabilization of the $\mathrm{C} / \mathrm{O}$ ratio close to 6.9 in Fig. 7a. These observations suggest that the reduction of $\mathrm{GO}$ mediated by $\mathrm{NaBH}_{4}$ acted preferentially and dominantly on the epoxy and/or hydroxyl groups and only to a lesser extent on the carbonyl groups. The steep increase in conductivity observed up to $\sim 10 \mathrm{~min}$ of reaction was thus primarily due to the reduction of $\mathrm{C}-\mathrm{O}$ rather than $\mathrm{C}=\mathrm{O}$ groups. This would explain the temporal discrepancy between the break point observed in the "C/O vs time" and "conductivity vs time" plots: the increase in conductivity decreased abruptly as soon as the reduction of $\mathrm{C}-\mathrm{O}$ groups was complete, although $\mathrm{C} / \mathrm{O}$ kept increasing due to the conversion of the $\mathrm{C}=\mathrm{O}$ groups. The fact that the percentage content of $\mathrm{C}-\mathrm{O}$ bond functionalities varied in a specular fashion with the sum of $\mathrm{Csp}^{2}$ and $\mathrm{Csp}^{3}$ (Fig. 9a) 
suggests that: i) the reduction of epoxy or hydroxyl groups had a greater impact on the restoration of the conductive nature of the graphite structure in the reduced GO; and ii) as shown by several studies, $\mathrm{sp}^{2}$ (graphenic domain with a low bandgap) and $\mathrm{sp}^{3}$ (oxidized domain with high bandgaps) regions coexist in $\mathrm{GO}^{31}$ with the $\mathrm{sp}^{2}$ graphenic regions exhibiting high conductivity (Klein tunneling), ${ }^{32}$ whereas the $\mathrm{sp}^{3}$ regions contribute with its semi-conducting properties. ${ }^{33}$ The specific mechanism for the elimination/removal of the oxygen units at the used $300 \mathrm{mM} \mathrm{NaBH}_{4}$ concentration may thus initially have progressed by formation and elimination of the boron oxide derivatives reported by Shin et al. ${ }^{34}$, whereas the evolution of the XPS data suggests that the reduction occurred first by epoxy group removal, de-esterification and de-hydration, and only at later stages removal of oxygen associated with ketones in the carbonyl groups. This explanation would be consistent with the ${ }^{13} \mathrm{C}$ NMR and XPS results presented by Gao et al. for conversion of graphite oxide into graphene. ${ }^{35}$

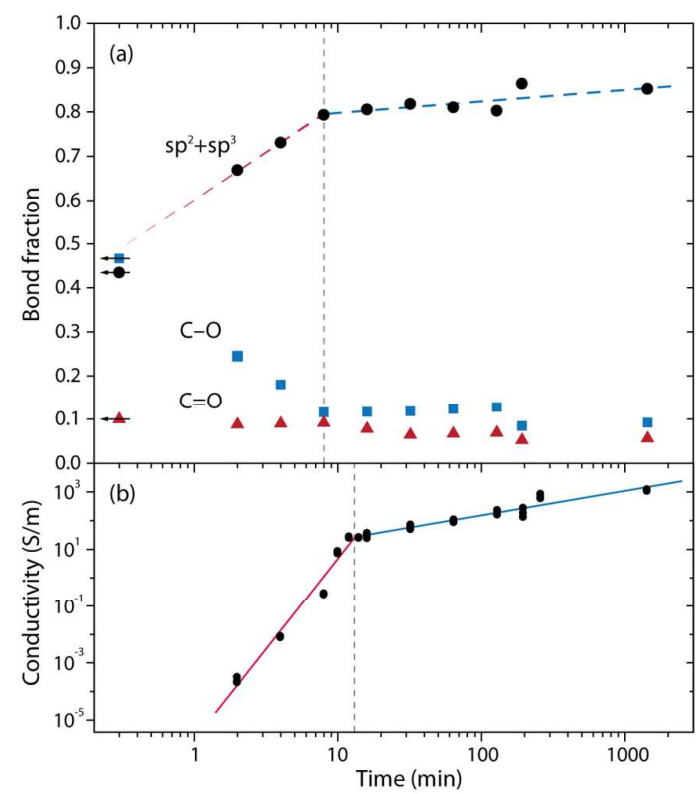

Fig. 9. (a) Evolution of $\left(\mathrm{Csp}^{2}+\mathrm{Csp}{ }^{3}\right), C-O$, and $C=O$ functional groups as a function of the reduction reaction time. (b) conductivity as a function of the reaction time (from Fig. 5).

Fig. 10 shows the Raman spectra $\left(1000-2000 \mathrm{~cm}^{-1}\right)$ of pristine $\mathrm{GO}$, and four representative $\mathrm{rGO}$ samples ( $\mathrm{rGO}$ after 2, 8, 32, and $128 \mathrm{~min}$ of reduction treatment), together with the spectra of pristine graphite. In the selected spectral range, two most significant peaks appear for $\mathrm{GO}$ and reduced samples tested, namely a G band at $\sim 1582 \mathrm{~cm}^{-1}$ and a D band centered at $\sim 1350 \mathrm{~cm}^{-1}$, which is consistent with the observations made by Stankovich et al. ${ }^{36}$. The Raman spectrum of the pristine graphite displays a prominent and sharper $G$ peak, with a less pronounced $D$ peak, as reported by Khan et al. ${ }^{37}$. The $\mathrm{G}$ band relates to the in-plane motion of the carbon atoms and is sensitive to strain effects, whereas the $D$ band relates to the presence of disorder and defects, either edges or topological

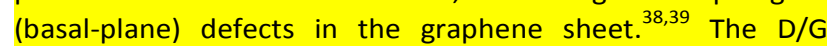

intensity ratio $\left(I_{D} / I_{G}\right)$ was here used as a diagnostic tool of the level of disorder in graphene and its derivatives. ${ }^{40}$ In the "low" defect density regime, the $I_{D} / I_{G}$ - values increase as a higher defect density creates more elastic scattering, whereas in the "high" defect density regime the $I_{D} / I_{G}$ will begin to decrease as an increasing defect density results in a more amorphous carbon structure, attenuating all Raman peaks. ${ }^{41}$ From the inset of Fig. 10, it can be seen that the $I_{D} / I_{G}$-value increased dramatically from the graphite powder $(0.16)$ to $\mathrm{GO}(0.91)$ but only moderately from $\mathrm{GO}$ to $\mathrm{rGOs}$, i.e. with increasing the chemical reduction treatment (from 1.078 for the $2 \mathrm{~min}$ treatment to 1.23 for the $128 \mathrm{~min}$ treatment). These values are higher compared with solvent exfoliation of graphite into graphene, ${ }^{42,43}$ but consistent with previous works on the chemical reduction of $\mathrm{GO}^{44}$ confirming the high concentrations of both basal and edge defects due to the harsh reduction process, proportional to the duration of the treatment.

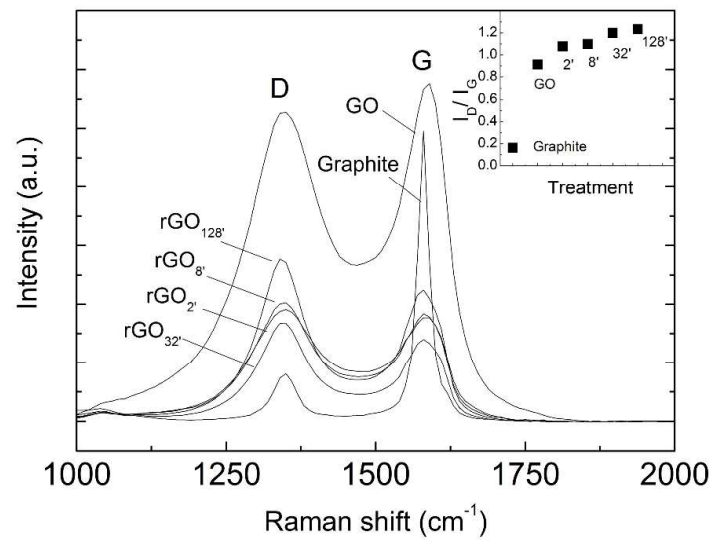

Fig. 10. Raman spectra of graphite, GO, and rGO obtained after 2, 8, 32, and 128 min treatment. The $I_{D} / I_{G}$ evolution as a function of the treatment type is shown in the inset.

By combining the above findings with those related to the electrical performance (Fig. 9b), it is suggested that the primary explanation to the observed differences in reaction progression rate during the reduction lies in the removal of the C-O functional groups (epoxy and/or hydroxyl groups), which had the greatest impact on the conductivity values and resulted in an increase in conductivity of more than 5 orders of magnitude during the first 8-12 min. Interestingly, these findings are in-line with the observation of a dramatic loss in structural stability of the rGO nanofoams after 8-12 minutes of reduction (in Fig. 6). Hydroxyl and other polar groups are important constituents in the association of inorganic particulate matter due to its strong interactions, and have previously been demonstrated as a responsible for the formation of nanoparticle foams. ${ }^{45}$ Upon their removal, the remaining carbonyl groups could not retain the integrity of the solid nanofoams, which in turn fragmented into a powder only by shaking the tubes that were used for drying. To some extent it is however possible that the porosity of the samples, increased defect density with reduction time, in combination 

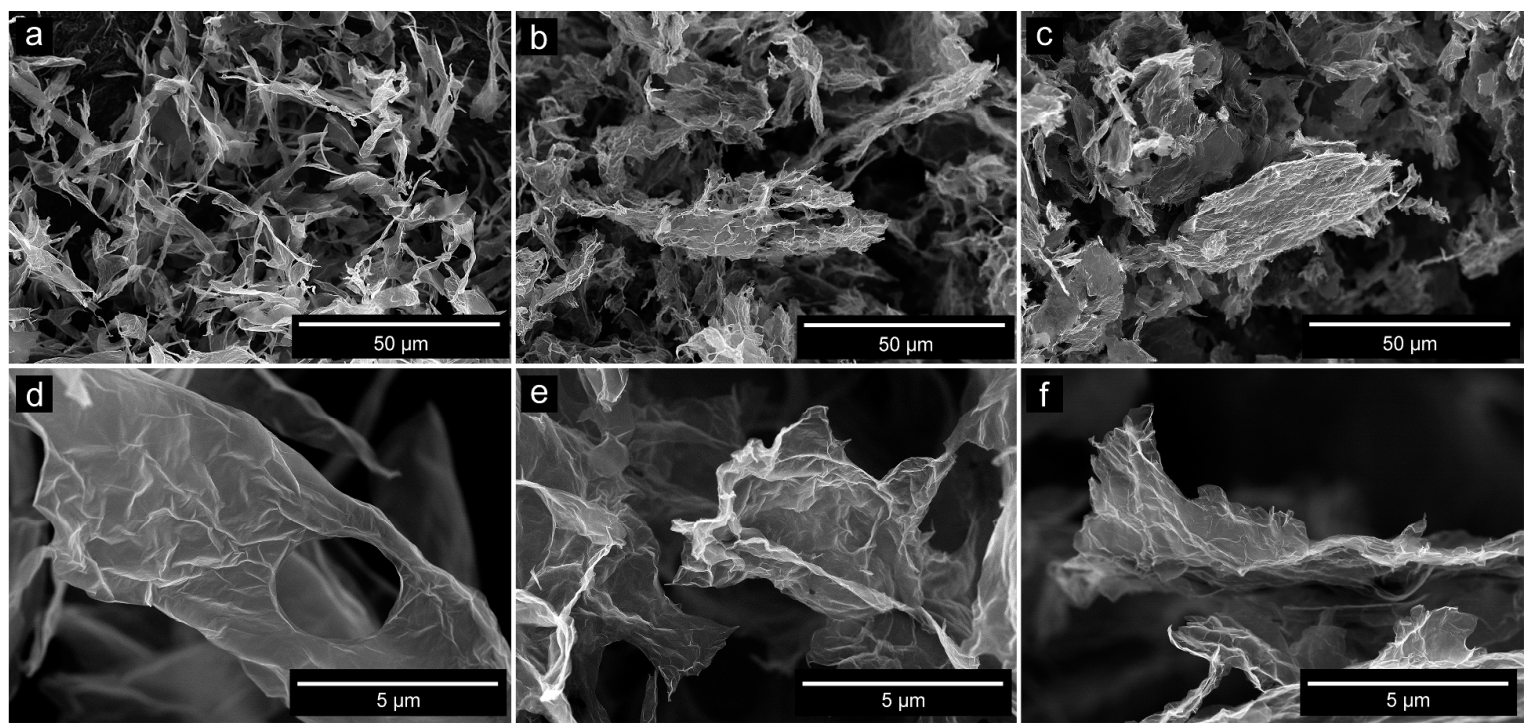

Fig. 11 The micrographs in the top row show 500 times magnified rGO reduced 2 min (a), 16 min (b) and 24 hours (c). The corresponding higher magnifications ( 5000 times) are displayed in the bottom row: $2 \mathrm{~min}(\mathrm{~d}), 16 \mathrm{~min}$ (e) and 24 hours (f).

with the observed morphological changes (Fig. 11 and 12), contributed to suppress the electrical performance of the conductive rGO sheet assemblies'.

\section{Morphologies changes with time during $\mathrm{GO}$ reduction}

Fig. 11 shows three $2 \mathrm{~mL}$ wet aliquots samples frozen by liquid nitrogen immediately after the removal of the residual counter ions from the synthesis salts. The samples are the 2 , 16 and 1440 minutes from Fig. 6, which show $0.0043,75$, and $1500 \mathrm{~S} / \mathrm{m}$ in conductivity. The average lateral sizes of the sheets were not possible to obtain from the 500x magnifications ( $a, b$ and $c$ ) due to the tendency of the sheets to aggregate with increasing reduction time. However, it is suggested that the size did not vary much for the individual sheets because the closer magnifications did not show any substantial size difference from the ca. $6 \pm 3 \mu \mathrm{m}$ lateral dimensions for the pristine GO (cf. Fig. 11d, e and $f$ with inset in Fig 1 in experimental section). It was also clear (from the 500x micrographs) that the pristine GO as well as the $2 \mathrm{~min}$ reduced GO samples contained 'rod-like' structural features; see Fig. 11a and Fig 1. These 'rod-like' morphologies are edges of the sheets that were more frequently visible in the freezedried samples from the shorter reduction times. To some extent their frequent representation was due to the improved dispersion that may have assisted in the formation of the nanofoams since they disappeared from the samples reduced for more than $16 \mathrm{~min}$ (Fig 6). Higher magnifications revealed that the rods were in fact swivelled/twisted larger sheets that often unfolded into relatively flat sheets, with a substructure of $0.5-1 \mu \mathrm{m}$ buckles (Fig. 11d and 12b). With more extended reduction times, the buckles became more frequent and showed more defined in-plane edges. Fig. 12 shows the smoother surface of the pristine GO before reduction, as compared to the buckled surface of the rGO sample reduced for 24 hours.
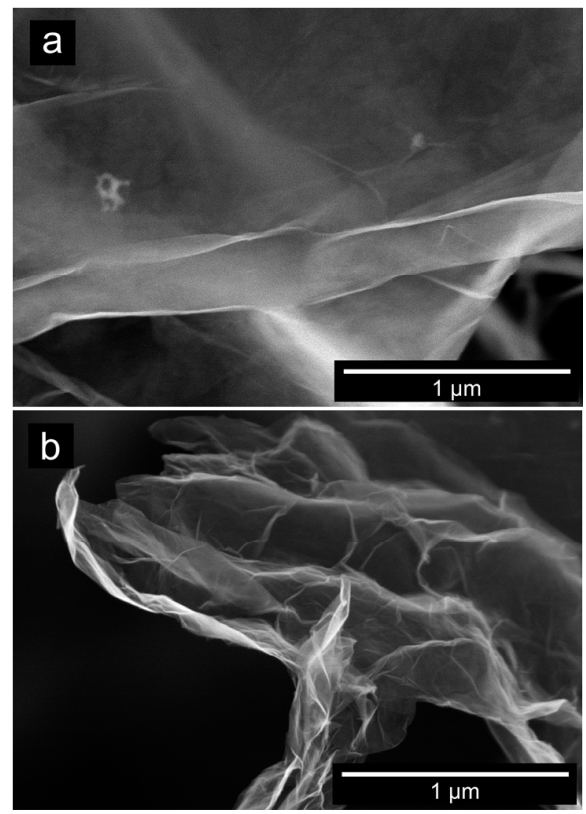

Fig. 12. (a) shows the pristine $\mathrm{GO}$ before reduction and (b) shows the reduced GO after 24 hours of reduction.

\section{Conclusions}

In this article we report the highest conductivity so far for reduced graphene oxide, using the inexpensive aqueous reduction route relying on sodium borohydride $\left(\mathrm{NaBH}_{4}\right)$. The measured conductivity values, and described requirements for establishing correct electrical data, show that after 24 hours of 
reduction a conductivity of $1500 \mathrm{~S} / \mathrm{m}$ can be expected, using a $300 \mathrm{mM} \mathrm{NaBH}$ solution. A vacuum filtration method is presented, using polycarbonate filter supports with submicron channels of $0.8 \mu \mathrm{m}$ in diameter, which resulted in 1 orders of magnitude higher conductivity compared to a sample dried without vacuum assistance, and 2 orders of magnitude higher conductivity compared to the same rGO obtained as a compacted freeze-dried substrate. The conductivity values accordingly relied on establishing an electrical characterization protocol, which takes into consideration the consolidation of the conductive rGO material into sheets with uniform thickness and using the 4-probe technique adjusted to the sample size, eliminating the influence of contact resistance. The record high $1500 \mathrm{~S} / \mathrm{m}$ for aqueous chemical reduction of GO represents ca. $15 \%$ of the highest reported conductivity of ca. $110000 \mathrm{~S} / \mathrm{m}$ demonstrated by Chen et al. using chemical vapour deposition (CVD) to obtain a compact conductive graphene paper, and ca. $45 \%$ of the reported conductivity for hydrazine $\left(\mathrm{N}_{2} \mathrm{H}_{2}\right)$ reduced graphene annealed at $500{ }^{\circ} \mathrm{C} .{ }^{48,49}$ It is also demonstrated herein that there is a clear correlation between the extent of reduction (manifested as increased conductivity and removal of oxygen) and the possibility to form a stable graphene nanofoam after freeze-drying. The pristine GO as well as the only partially reduced GO could easily be frozen into a solid that with elimination of the water phase became a brownish/black foam, whereas all samples reduced for more than 16 minutes collapsed into a powder under identical freeze-drying conditions. Finally, high resolution XPS data allowed an explanation to the observed 2 phase reaction progress behaviour, which initially occurred by dominant removal of epoxy and hydroxyl groups. The results pave the way for applied use of rGO as a filler material in conductive polymer composites, with predictable electrical data prior to the composite preparation.

\section{Acknowledgements}

The authors acknowledge the exchange program between Royal Institute of Technology (KTH, Sweden), École Polytechnique Fédérale de Lausanne (EPFL, Switzerland) and École Nationale Supérieure des Mines de Paris (ENSMP, France) for providing the opportunity to experience research work within the undergraduate program. R. L. Andersson acknowledges financial support from: European Institute of Innovation and Technology (EIT) - KIC InnoEnergy and Swedish Centre for Smart Grids and Energy Storage (SweGRIDS).

\section{References}

1 J. R. Potts, D. R. Dreyer, C. W. Bielawski and R. S. Ruoff, Polymer, 2011, 52, 5-25.

2 R. Verdejo, F. Barroso-Bujans, M. A. Rodriguez-Perez, J. Antonio de Saja and M. A. Lopez-Manchado, J. Mater. Chem., 2008, 18, 2221-2226.

3 M. Fang, K. Wang, H. Lu, Y. Yang and S. Nutt, J. Mater. Chem., 2009, 19, 7098-7105.
4 C. Lee, X. Wei, J. W. Kysar and J. Hone, Science, 2008, 321, 385-388.

5 R. Shah, T. Datashvili, T. Cai, J. Wahrmund, B. Menard, K. P. Menard, W. Brostow and J. M. Perez, Mater. Res. Innovat., 2015, 19, 97-106.

6 W. S. Hummers and R. E. Offeman, JACS, 1958, 80, 13391339.

7 A. Lerf, H. He, M. Forster and J. Klinowski, J. Phys. Chem. B, 1998, 102, 4477-4482.

8 Z. Wang, J. K. Nelson, H. Hillborg, S. Zhao and L. S. Schadler, Adv. Mater., 2012, 24, 3134-3137.

9 H. Pang, T. Chen, G. Zhang, B. Zeng and Z.-M. Li, Mater. Lett., 2010, 64, 2226-2229.

10 H. -B. Zhang, W. -G. Zheng, Q. Yan, Y. Yang, J. -W. Wang, Z. H. Lu, G. -Y. Ji and Z. -Z. Yu, Polymer, 2010, 51, 1191-1196.

11 H. Gómez, M. K. Ram, F. Alvi, P. Villalba, E. Stefanakos and A. Kumar, J. Power Sources, 2011, 196, 4102-4108.

12 C. K. Chua and M. Pumera, Chem. Soc. Rev., 2014, 43, 291312.

13 M. J. Fernández-Merino, L. Guardia, J. I. Paredes, S. VillarRodil, P. Solís-Fernández, A. Martínez-Alonso and J. M. D. Tascón, J. Phys. Chem. C, 2010, 114, 6426-6432.

14 W. Gao, L. B. Alemany, L. Ci and P. M. Ajayan, Nat. Chem., 2009, 1, 403-408.

15 M. Yoonessi and J. R. Gaier, ACS Nano, 2010, 4, 7211-7220.

16 C.-t. F. Lo, K. Karan and B. R. Davis, Ind. Eng. Chem. Res., $2007,46,5478-5484$

17 F. Smits, Bell Syst. Tech. J., 1958, 37, 711-718.

18 L. B. Valdes, Proc. IEEE, 1954, 42, 420-427.

19 Z. Yang, H. Yan, H. Yang, H. Li, A. Li and R. Cheng, Water Res., 2013, 47, 3037-3046.

20 J. Liu, P. Li, H. Xiao, Y. Zhang, X. Shi, X. Lü and X. Chen, AIP Advances, 2015, 5, 117151.

21 B. Marinho, M. Ghislandi, E. Tkayla, C. E. Koning and G. de With, Powder Technol., 2012, 221, 351-358.

22 H. O. Pierson, in Handbook of Carbon, Graphite, Diamonds and Fullerenes: Processing and Applications, Noyes Publications, Park Ridge, New Jersey, USA, 1993, ch.3, pp. 52 and 61.

23 H.C. Bi, K.B. Yin, X. Xie, J. Ji, S. Wan, L.T. Sun, M. Terrones and M.S. Dresselhaus, Sci. Rep., 2013, 3, 2714:1-7.

24 R. Wang, H. Gao, D. Zhu, T. Yang, X. Zhang, L. Li, G. Yin, L. Zhu, Z. Feng and X. Li, Carbon, 2017, 114, 23-30.

25 A. M. Pourrahimi, D. Liu, L. K. H. Pallon, R. L. Andersson, A. Martinez Abad, J. M. Lagaron, M. S. Hedenqvist, V. Strom, U. W. Gedde and R. T. Olsson, RSC Adv., 2014, 4, 35568-35577. 
26 D. Kashyap, K.H. Park, and M. Dhayal, RSC Adv., 2015, 5, 95657-95665.

27 I. U. Unalan, C. Wan, L. Figiel, R. T. Olsson, S. Trabattoni S, S. Farris, Nanotechnology, 2015, 26, 275703.

28 A. Ganguly, S. Sharma, P. Papakonstantinou, J. Hamilton, J. Phys. Chem. C, 2011, 115, 17009-19.

29 G. Sobon, J. Sotor, J. Jagiello, R. Kozinski, M. Zdrojek, M. Holdynski, P. Paletko, J. Boguslawski, L. Lipinska, R. M. Abramski, Opt. Express, 2012, 20, 19463-73.

30 D. Yang, A. Velamakanni, G. Bozoklu, S. Park, M. Stoller, R. D. Piner, S. Stankovich, I. Jung, D.A. Field, C. A. Ventrice, R. S. Ruoff, Carbon, 2009, 47, 145-52.

31 G. Eda, Y. Y. Lin, C. Mattevi, H. Yamaguchi, H.A. Chen, I. S. Chen, C.W. Chen, M. Chhowalla, Adv. Mater., 2010, 22, 50509.

32 M.I. Katsnelson, K.S. Novoselo, A.K. Geim, Nature Phys., 2006, 2, 620-25.

33 D.C. Elias, R.R. Nair, T. M. G. Mohiuddin, S. V. Morozov, P. Blake, M. P. Halsall, A.C. Ferrari, D.W. Boukhvalov, M.I. Katsnelson, A.K. Geim, K.S. Novoselo, Science, 2009, 323, 610-13.

34 H. J. Shin, K. K. Kim, A. Benayad, S. M. Yoon, H. K. Park, I. S. Jung, M. H. Jin, H. K. Jeong, J. M. Kim, J. Y. Choi and Y. H. Lee, Adv. Funct. Mater., 2009, 19, 1987-1992

35 W. Gao, L. B. Alemany, L. Ci and M. Ajayan, Nat. Chem., 2009, 1, 403-407.

36 S. Stankovich, D. A. Dikin, R. D. Piner, K. A. Kohlhaas, A. Kleinhammes, Y. Jia, Y. Wu, S. T. Nguyen and R. S. Ruoff, Carbon, 2007, 45, 1558-1565.

37 U. Khan, A. O'Neill, M. Lotya, S. De and J. N. Coleman, Small 2010, 6, 864-871.

38 D. Graf, F. Molitor, K. Ensslin, C. Stampfer, A. Jungen, C. Hierold and L. Wirtz, Nano Lett., 2007, 7, 238-242.

39 C. Casiraghi, A. Hartschuh, H. Qian, S. Piscanec, C. Georgi, A. Fasoli, K. S. Novoselov, D. M. Basko and A. C. Ferrari, Nano Lett., 2009, 9, 1433.

40 A. C. Ferrari, Solid State Commun., 2007, 143, 47-57.

41 M. M. Lucchese, F. Stavale, E. H. Ferreira, C. Vilani, M. V. O. Moutinho, R. B. Capaz, C. A. Achete and A. Jorio, Carbon 2010, 48, 1592-1597.

42 J. Fan, Z. Shi, Y. Ge, J. Wang, Y. Wang and J. Yin, J. Mater. Chem., 2012, 22, 13764-13772.

43 I. U. Unalan, C. Wan, S. Trabattoni, L. Piergiovanni and S. Farris, RSC Adv., 2015, 5, 26482-26490.

44 V. Chabot, B. Kim, B. Sloper, C. Tzoganakis and A. Yu, Sci. Rep., 2013, 3, 1378.
45 L. K. H. Pallon, R. T. Olsson, D. Liu, A. M. Pourrahimi, M. S. Hedenqvist, A. T. Hoang, S. Gubanski and U. W. Gedde, J. Mater. Chem. A, 2015, 3, 7523-7534.

46 Y. Si and E. T. Samulski, Nano Lett., 2008, 8, 1679-1682.

47 H. J. Shin, K. K. Kim, A. Benayad, S. M. Yoon, H. K. Park, I. S. Jung, M. H. Jin, H. K. Jeong, J. M. Kim, J. Y. Choi and Y. H. Lee, Adv. Funct. Mater., 2009, 19, 1987-1992.

48 J. Chen, H. Bi, S. Sun, Y. Tang, W. Zhao, T. Lin, D. Wan, F. Huang, X. Zhou, X. Xie and M. Jiang, ACS Appl. Mater. Interfaces, 2013, 5, 1408-1413.

49 H. Chen, M. B. Müller, K. J. Gilmore, G. G. Wallace and D. Li, Adv. Mater., 2008, 20, 3557-3561. 


\section{Supplementary information:}

\section{Experimental review: Chemical reduction of graphene oxide (G0) to reduced graphene oxide (rG0) by aqueous chemistry}

L. G. Guex, ${ }^{a}$ B. Sacchi, ${ }^{b}$ K. F. Peuvot, ${ }^{a}$ R. L. Andersson, ${ }^{a}$ A. M. Pourrahimi, V. Ström, ${ }^{,}$S. Farris, ${ }^{d}$ and R. T. Olsson ${ }^{a}, \dagger$

Table S1. Assignment and relative percentage of the functionalities arising from the deconvolution of the C 1s XPS spectra.

\begin{tabular}{|c|c|c|c|}
\hline Sample & $\begin{array}{c}\text { Peak BE } \\
(\mathrm{eV})\end{array}$ & $\%$ & Functionalities \\
\hline \multirow[t]{4}{*}{ GO } & 284.6 & 27.11 & $C-C\left(\mathrm{sp}^{2}\right)$ \\
\hline & 285.6 & 16.28 & $C-C\left(\mathrm{sp}^{3}\right)$ \\
\hline & 286.9 & 46.65 & $\mathrm{C}-\mathrm{O}$ \\
\hline & 288.8 & 9.95 & $\mathrm{C}=\mathrm{O}$ \\
\hline \multirow[t]{4}{*}{$\mathrm{rGO}_{2^{\prime}}$} & 284.5 & 46.96 & $\mathrm{C}-\mathrm{C}\left(\mathrm{sp}^{2}\right)$ \\
\hline & 285.3 & 19.86 & $\mathrm{C}-\mathrm{C}\left(\mathrm{sp}^{3}\right)$ \\
\hline & 286.8 & 24.42 & $\mathrm{C}-\mathrm{O}$ \\
\hline & 288.9 & 8.76 & $\mathrm{C}=0$ \\
\hline \multirow[t]{4}{*}{$\mathrm{rGO}_{4^{\prime}}$} & 284.6 & 50.62 & $\mathrm{C}-\mathrm{C}\left(\mathrm{sp}^{2}\right)$ \\
\hline & 285.3 & 22.45 & $\mathrm{C}-\mathrm{C}\left(\mathrm{sp}^{3}\right)$ \\
\hline & 286.9 & 17.98 & $\mathrm{C}-\mathrm{O}$ \\
\hline & 288.8 & 8.95 & $\mathrm{C}=\mathrm{O}$ \\
\hline \multirow[t]{4}{*}{$\mathrm{rGO}_{8^{\prime}}$} & 284.6 & 54.28 & $\mathrm{C}-\mathrm{C}\left(\mathrm{sp}^{2}\right)$ \\
\hline & 285.7 & 25.03 & $\mathrm{C}-\mathrm{C}\left(\mathrm{sp}^{3}\right)$ \\
\hline & 287.0 & 11.54 & $\mathrm{C}-\mathrm{O}$ \\
\hline & 288.8 & 9.15 & $\mathrm{C}=\mathrm{O}$ \\
\hline \multirow[t]{4}{*}{$\mathrm{rGO}_{16^{\prime}}$} & 284.6 & 57.00 & $\mathrm{C}-\mathrm{C}\left(\mathrm{sp}^{2}\right)$ \\
\hline & 285.5 & 23.54 & $\mathrm{C}-\mathrm{C}\left(\mathrm{sp}^{3}\right)$ \\
\hline & 286.9 & 11.65 & $\mathrm{C}-\mathrm{O}$ \\
\hline & 288.8 & 7.81 & $\mathrm{C}=\mathrm{O}$ \\
\hline \multirow[t]{4}{*}{$\mathrm{rGO}_{32^{\prime}}$} & 284.6 & 59.72 & $\mathrm{C}-\mathrm{C}\left(\mathrm{sp}^{2}\right)$ \\
\hline & 285.6 & 22.05 & $\mathrm{C}-\mathrm{C}\left(\mathrm{sp}^{3}\right)$ \\
\hline & 287.0 & 11.76 & $\mathrm{C}-\mathrm{O}$ \\
\hline & 288.8 & 6.47 & $\mathrm{C}=\mathrm{O}$ \\
\hline \multirow[t]{4}{*}{$\mathrm{rGO}_{64^{\prime}}$} & 284.6 & 58.96 & $C-C\left(\mathrm{sp}^{2}\right)$ \\
\hline & 285.6 & 22.07 & $\mathrm{C}-\mathrm{C}\left(\mathrm{sp}^{3}\right)$ \\
\hline & 287.0 & 12.28 & $\mathrm{C}-\mathrm{O}$ \\
\hline & 288.9 & 6.69 & $\mathrm{C}=\mathrm{O}$ \\
\hline \multirow[t]{4}{*}{$\mathrm{rGO}_{128^{\prime}}$} & 284.6 & 58.19 & $\mathrm{C}-\mathrm{C}\left(\mathrm{sp}^{2}\right)$ \\
\hline & 285.6 & 22.09 & $\mathrm{C}-\mathrm{C}\left(\mathrm{sp}^{3}\right)$ \\
\hline & 287.0 & 12.80 & $\mathrm{C}-\mathrm{O}$ \\
\hline & 288.9 & 6.91 & $\mathrm{C}=\mathrm{O}$ \\
\hline \multirow[t]{4}{*}{$\mathrm{rGO}_{192^{\prime}}$} & 284.6 & 64.42 & $C-C\left(\mathrm{sp}^{2}\right)$ \\
\hline & 285.6 & 21.95 & $C-C\left(\mathrm{sp}^{3}\right)$ \\
\hline & 287.0 & 8.45 & $\mathrm{C}-\mathrm{O}$ \\
\hline & 288.9 & 5.19 & $\mathrm{C}=\mathrm{O}$ \\
\hline \multirow[t]{4}{*}{$\mathrm{rGO}_{1440^{\prime}}$} & 284.6 & 63.40 & $C-C\left(\mathrm{sp}^{2}\right)$ \\
\hline & 285.6 & 21.77 & $\mathrm{C}-\mathrm{C}\left(\mathrm{sp}^{3}\right)$ \\
\hline & 286.9 & 9.18 & $\mathrm{C}-\mathrm{O}$ \\
\hline & 288.8 & 5.65 & $\mathrm{C}=0$ \\
\hline
\end{tabular}


Experimental review: Chemical reduction of graphene oxide (G0) to reduced graphene oxide (rG0) by aqueous chemistry

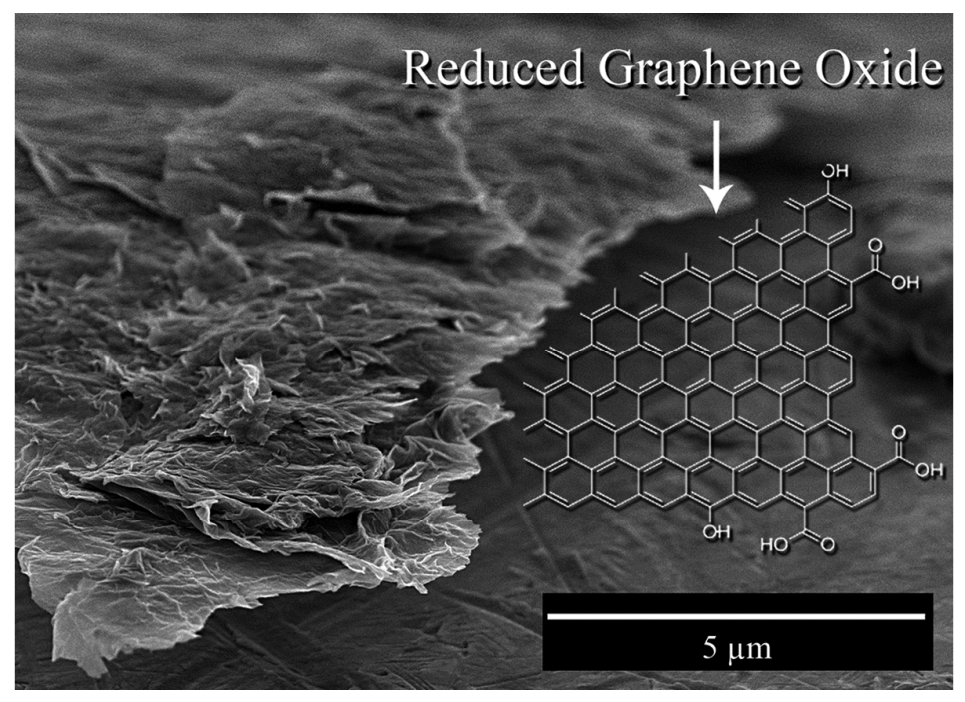

TOC text:

An experimental review of $\mathrm{NaBH}_{4}$ graphene oxide sheet reduction is presented, with consideration to elimination of oxygen and the morphological nature of the stacked sheets as a substrate for electrical conductivity measurements. A conductivity of $1500 \mathrm{~S} / \mathrm{m}$ was reached with the provided protocol, which is record high for $\mathrm{NaBH}_{4}$ as a reducing agent. 